\title{
Timing of Perennial Canker Development in Apple Trees Caused by Neofabraea perennans and Neofabraea kienholzii
}

\author{
Christian G. Aguilar, ${ }^{1}$ Mark Mazzola, ${ }^{2, \dagger}$ and Chang-Lin Xiao ${ }^{3}$ \\ ${ }^{1}$ Department of Plant Pathology, Washington State University, Pullman, WA 99164; ${ }^{2}$ Tree Fruit Research Laboratory, United \\ States Department of Agriculture-Agricultural Research Service (USDA-ARS), Wenatchee, WA 98801; and ${ }^{3}$ San Joaquin Valley \\ Agricultural Sciences Center, USDA-ARS, Parlier, CA 93648
}

\begin{abstract}
Members of the genera Neofabraea and Phlyctema have been reported to incite canker diseases of apple trees and a postharvest decay of apple fruit referred to as "bull's-eye rot." Neofabraea kienholzii was recently identified as participating in the bull's-eye rot disease complex of apple and other pome fruit. In this study, apple twigs inoculated with $N$. kienholzii were shown to develop symptoms of a canker disease closely resembling perennial canker of pome fruit trees caused by $N$. perennans. Cankers resulting from infection by either Neofabraea spp. were more likely to be induced when twig inoculations occurred in October, and to a lesser degree in April, compared with all other inoculation dates evaluated in this study. Although $N$. kienholzii tended to induce cankers that were smaller in size

compared with $N$. perennans, both pathogens shared similar seasonal trends in the initiation and expansion of tree cankers. $N$. perennans and $N$. kienholzii were recovered from inoculated twigs 6 months postinoculation regardless of when inoculations were conducted, indicating that both pathogens can survive on diseased twigs yearround. In addition, acervuli were observed more often on twigs inoculated in September and April compared with those inoculated in other months. Data from this work should help further our understanding of the epidemiology of $N$. kienholzii. This information also highlights the importance of proper branch pruning, canker removal, and aphid control. Such management activities should be conducted in a manner that helps minimize further spread of the pathogen.
\end{abstract}

Neofabraea kienholzii (Seifert, Spotts and Lévesque) Spotts, Lévesque \& Seifert, N. malicorticis (Cordley) H.S. Jacks, N. perennans Kienholz, and Phlyctema vagabunda Desm. (previously regarded as N. alba [E.J. Guthrie] Verkley [Chen et al. 2016]) are four economically important phytopathogenic fungi limiting pome fruit production in Washington State, U.S.A., and throughout the world (Henriquez et al. 2004). The fungi cause a postharvest fruit decay of apples and pears commonly referred to as "bull's-eye rot" in North America, or sometimes called "lenticel rot" in Europe (Cameldi et al. 2014). Symptoms of the disease include the development of firm, circular lesions on the fruit skin originating at open lenticels and extending to the fruit flesh. Lesions display a diagnostic "bull'seye" appearance having rings of alternating dark and light brown pigmentation visible throughout the lesion or with darker pigmentation confined to along the margin of the lesion (Kidd and Beaumont 1924; Vico et al. 2016).

In addition to inciting fruit decay, $N$. malicorticis and $N$. perennans yield similar, yet distinct canker diseases of apple fruit trees. The fungus initiates an aggressive canker disease via direct penetration of bark tissue, inciting a disease called "anthracnose canker" or "fiddle string canker" (Childs 1929). Cankers appear as sunken, oval-

${ }^{\dagger}$ Corresponding author: Mark Mazzola; E-mail: mark.mazzola@ars.usda.gov

Funding: Financial assistance was provided by the Achievement Rewards for College Scientists (ARCS) program and the Research Assistantship for Diverse Scholars (RADS) program available at Washington State University, the Washington Tree Fruit Research Commission, and the United States Department of Agriculture, Agricultural Research Service (USDA-ARS).

Mention of trade names or commercial products in this article is solely for the purpose of providing specific information and does not imply recommendations or endorsement by the U.S. Department of Agriculture. USDA is an equal opportunity provider and employer.

Accepted for publication 27 September 2018.

This article is in the public domain and not copyrightable. It may be freely reprinted with customary crediting of the source. The American Phytopathological Society, 2019. shaped depressions of bark tissue with reddish-orange to purple discoloration. Over time, cankers may expand to completely girdle tree limbs, causing twig dieback. Infected tissue within the canker may crack and eventually fall off, revealing the stringy bast fibers underneath (Cordley 1900; Pscheidt and Ocamb 2016). The disease is common throughout coastal Washington, where frequent rain events and mild temperatures create an ideal environment for growth and dissemination of the fungus (Kienholz 1939).

Perennial canker caused by $N$. perennans is prevalent throughout central and eastern Washington, where apples are grown in a semiarid climate. The fungus can withstand the hot, dry summers and freezing winter conditions encountered east of the Cascade Mountain Range (Kienholz 1939). Unlike $N$. malicorticis, $N$. perennans requires wounds to enter and colonize the woody tissue of its host. Symptoms of perennial canker are similar to those of anthracnose canker, especially during the initial stages of development. However, as perennial cankers expand, the infected tree reacts by forming rings of callus tissue along the canker periphery. The callus tissue serves as a physical barrier to block off the fungus and prevent further colonization into healthy tissue. However, repeated feeding by the woolly apple aphid, Eriosoma lanigerum, along with winter injury and pruning wounds, exacerbate the disease by providing annual points of reentry for fungal invasion, thus allowing the fungus to persist in a pseudo perennial manner (Childs 1929; Grove 1990; Zeller and Childs 1925).

Phlyctema vagabunda has been documented causing twig dieback and small, superficial cankers of apple (Rooney-Latham and Soriano 2016) and pear trees (Henriquez et al. 2006); however, the fungus can also survive as a saprophyte of dead bark (Verkley 1999), leaf matter (Tan and Burchill 1972), fruiting spurs (Gutherie 1959), and pruning stubs (Henriquez et al. 2004) of pome fruit trees. Cankers incited by $P$. vagabunda appear as small, elliptical depressions exhibiting cracking and peeling of necrotic bark tissue (Henriquez et al. 2006). Similar to $N$. perennans, $P$. vagabunda requires wounds as entry points to colonize woody tissue of deciduous fruit trees. In addition to limiting pome fruit production, $P$. vagabunda also causes a damaging fruit spot disease of olive fruit (Rooney-Latham et al. 2013), branch cankers of olive trees (Romero et al. 2016), and coin canker of ash trees (Putnam and Adams 2005), demonstrating a much wider host range than its sibling taxa. 
By forming canker associations, bull's-eye rot fungi are able to withstand unfavorable environmental conditions encountered in the orchard, allowing for the annual survival of these fungi. Depending on canker location (lateral branches versus tree trunk) and severity of the disease, cankers can cause girdling of tree limbs that may severely impair host health, reduce fruit productivity, or, at worst, completely kill trees (Garton et al. 2016). Cankers have been shown to sporulate throughout the year for several years (Grove et al. 1992; Henriquez et al. 2006), providing copious levels of inoculum for subsequent fruit infection.

Although bull's-eye rot and its associated canker diseases have been documented in the scientific literature at least since the early 20th century (Cordley 1900), N. kienholzii was only recently identified as a fourth fungus participating in this disease complex near the turn of the 21st century (de Jong et al. 2001). Originally recovered from an infected apple grown in Portugal and an apple tree canker originating from Nova Scotia, Canada (de Jong et al. 2001), the fungus has since been detected in Washington (Spotts et al. 2009) and elsewhere throughout the Pacific Northwest (Henriquez et al. 2004; Spotts et al. 2009). Given the importance of apple production in Washington, and general lack of information pertaining to the survivability and life history of $N$. kienholzii in the Pacific Northwest, wound inoculation studies were conducted on apple trees in an effort to monitor the survival capabilities of $N$. kienholzii in apple orchards. Because $N$. kienholzii currently shares a similar geographic distribution with that of $N$. perennans in Washington (Spotts et al. 2009), inoculations using $N$. perennans were simultaneously conducted as a reference for canker development. The primary objectives of this study were to (i) demonstrate whether $N$. kienholzii could incite cankers following artificial inoculation of wounded apple twigs and (ii) determine whether cankers developed in a seasonal manner similar to that displayed by perennial canker (Grove et al. 1992; Henriquez et al. 2006). Specifically, the progress of canker development in response to artificial wound inoculations with $N$. kienholzii and N. perennans was compared to identify the most favorable timing for canker initiation and canker expansion. In addition, year-round fungal survival in the woody tissue of apple twigs was assessed. Similarly, the timing of asexual fruiting body development by Neofabraea spp. was monitored in apple twigs during spring and autumn months.

\section{Materials and Methods}

Canker induction and expansion. Canker expansion studies were performed on 'Fuji' and 'Red Delicious' apple trees planted in 2007 at the Washington State University Sunrise Research Orchard (SR) near Palisades, WA, U.S.A. $\left(47^{\circ} 25^{\prime} 08^{\prime \prime} \mathrm{N}, 119^{\circ} 54^{\prime}\right.$ $\left.52^{\prime \prime} \mathrm{W}\right)$. The first inoculation was conducted on 23 April 2012 and continued every 8 to 9 weeks until 18 February 2015. A single annual trial consisted of inoculations beginning in April and continuing until February of the following year. At each inoculation date, 16 trees of each cultivar were randomly selected. Three 1-year-old twigs from each tree were wounded and inoculated with a sterile agar plug (control), an agar plug containing germinated spores of $N$. kienholzii, and an agar plug containing germinated spores of $N$. perennans following a randomized complete block design, with tree serving as the block. Details of twig inoculation and canker expansion measurements are described below.

Isolates CLX5396 (N. perennans) and CLX4426 (N. kienholzii) were used for twig inoculation in this study. CLX5396 originated from decayed 'Gala' apple fruit collected from an orchard in East Wenatchee, WA, U.S.A., and CLX4426 originated from decayed Fuji apple fruit from an orchard in Tonasket, WA, U.S.A. Selection

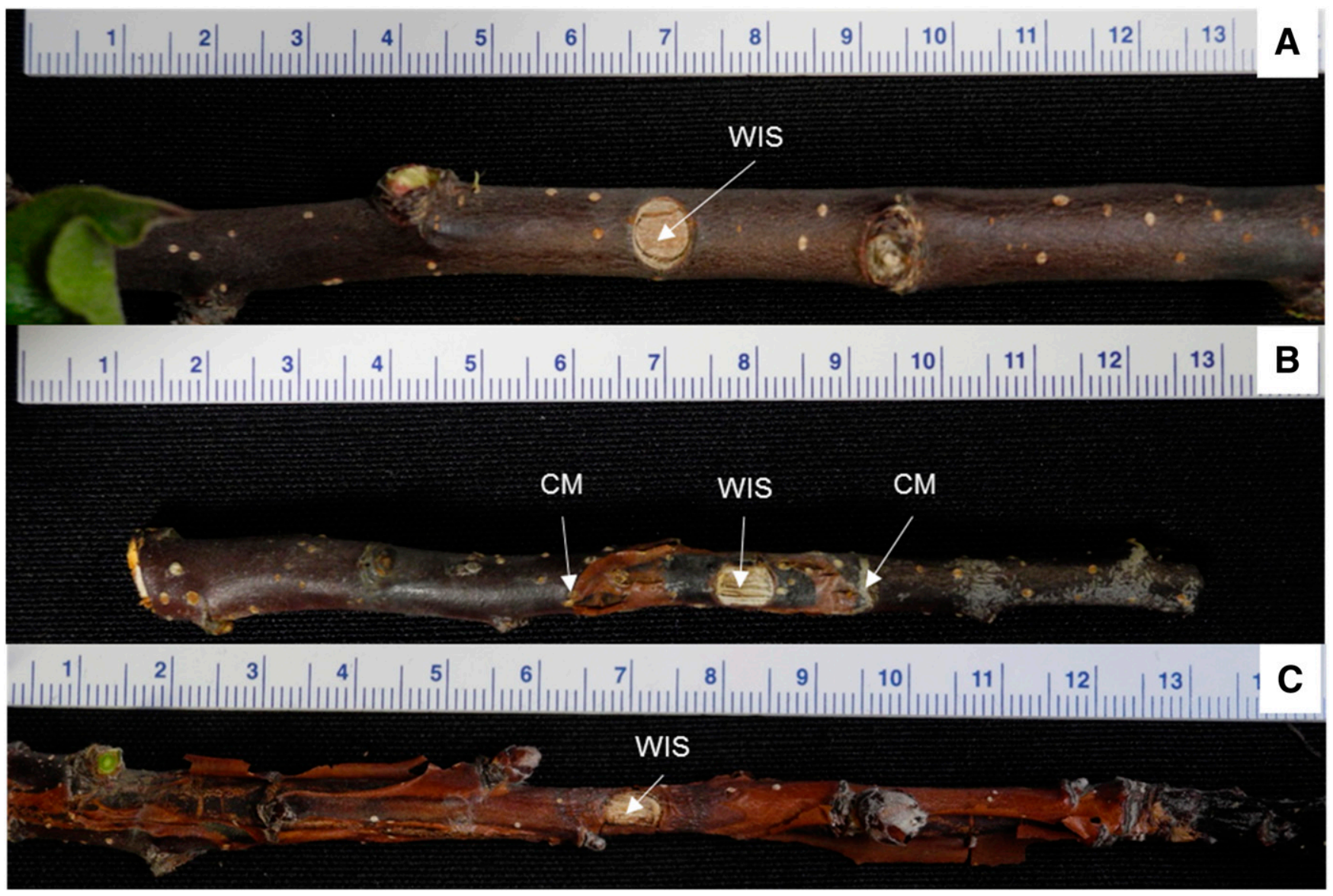

Fig. 1. Physiological response of Fuji apple twigs to wounding and artificial inoculation during the month of October with a sterile potato dextrose agar (PDA) plug serving as the control treatment (A), a PDA plug containing germinated spores of Neofabraea kienholzii (B), and a PDA plug containing germinated spores of N. perennans (C). Arrows indicating the wound inoculation site (WIS) and canker margin (CM) are shown. Twigs were harvested and photos taken at 6 months postinoculation. 
of these isolates was based on species identity using morphological (Dugan et al. 1993; Kienholz 1939; Verkley 1999) and molecular (Gariépy et al. 2003; Soto-Alvear et al. 2013) diagnostics. Mycelia from each isolate were preserved on plugs of potato dextrose agar (PDA; Difco, Becton, Dickinson and Company, Sparks, MD) suspended in a $15 \%$ glycerol solution and stored at $-80^{\circ} \mathrm{C}$.

The fungal isolates were revived from $-80^{\circ} \mathrm{C}$ stocks onto fresh PDA. After incubation at $20^{\circ} \mathrm{C}$ for 21 days, $10 \mathrm{ml}$ of sterile water was added to each culture plate, and a sterile inoculation loop was lightly brushed over the top of each culture to displace conidia into suspension. The conidial suspension was passed through two layers of sterile cheesecloth to filter out mycelial and agar fragments. The concentration of the conidial suspension was adjusted to $5 \times 10^{4}$ spores per milliliter using a hemocytometer and sterile water. Agar plugs were excised from sterile PDA plates using a 5-mm-diameter cork borer and transferred to a sterile container. Ten microliters of conidial suspension was added to the top of each agar plug and subsequently incubated at $20^{\circ} \mathrm{C}$ without light for $48 \mathrm{~h}$ to allow for conidial germination.

On the day of inoculation, twigs were surface disinfested with $70 \%$ ethanol and injured roughly midlength along the twig using a 5-mmdiameter cork borer. Injuries were superficial, exposing the inner bark tissue. Inoculum plugs were placed conidia side down onto the wound so that spores were positioned in direct contact with woody tissue. Small squares of sterile moistened cheesecloth (approximately $25 \mathrm{~mm}^{2}$ ) were set on top of inoculum plugs and held in place by wrapping Parafilm around the twig. The inoculum plug was removed from the wound site after 21 days.

After inoculation, half-length canker measurements were recorded every 4 weeks for up to 6 months. The half-length measurement is herein defined as the distance from the center of the wound inoculation site to the proximal end of the canker. Twigs exhibiting symptoms of dieback developed necrotic tissue extending from the inoculation site to the distal end of the twig, making it difficult to discern the canker margin. Half-length canker measurements were preferred in order to avoid overestimations of canker length, especially when twig dieback symptoms were severe. On the sixth month postinoculation, twigs were harvested from each tree, and cankers were surface disinfested in a $1 \%$ sodium hypochlorite solution for 3 min followed by washing with deionized water three times for $1 \mathrm{~min}$ each wash. Seven to 10 tissue subsamples were excised from the margin of twig cankers using a sterile scalpel and incubated at $20^{\circ} \mathrm{C}$ on PDA for 14 days to visually verify the presence of each Neofabraea fungus. Recovery of $N$. perennans and $N$. kienholzii was recorded in an effort to assess the survival rate of Neofabraea spp. from inoculated tissues, and in partial fulfillment of Koch's postulates.

Canker half-length measurements recorded at 6 months postinoculation were wound corrected by subtracting $2.5-\mathrm{mm}$ length from each measurement to account for tissue damage induced by the cork borer during the inoculation process. Measurements were then log transformed to normalize the data and were analyzed using a generalized mixed linear model in SAS PROC MIXED (version 9.4; SAS Institute, Cary, NC). The variables of interest were whether inoculation date and/or pathogen treatment (control, $N$. perennans, $N$. kienholzii) had any influence over canker expansion, with tree representing the random effect of the model. The Tukey method was used to differentiate means considered statistically significant from one another $(P \leq 0.05)$. When a significant interaction between the two explanatory variables in the model was identified, analyses were split to compare the individual effects of all treatment levels for each variable of interest. Fisher's exact test was used to compare differences in pathogen recovery between the two inoculum sources across each inoculation date using SAS PROC FREQ $(P \leq 0.05)$. Data pertaining to pathogen recovery from twigs inoculated in February and April 2014 were unavailable and therefore not used in the conduct of these comparisons.

Fruiting body development. Fruiting body evaluation studies were conducted on Fuji apple trees planted in 1993 at the Washington State University Tree Fruit Research and Extension Center orchard (TFREC) in Wenatchee, WA, U.S.A. $\left(47^{\circ} 26^{\prime} 26^{\prime \prime} \mathrm{N}, 120^{\circ} 21^{\prime} 10^{\prime \prime} \mathrm{W}\right)$ and on Fuji trees planted in 1999 at the Washington State University Columbia View Research orchard (CV) in East Wenatchee, WA, U.S.A. $\left(47^{\circ} 33^{\prime} 44^{\prime \prime} \mathrm{N}, 120^{\circ} 14^{\prime} 55^{\prime \prime} \mathrm{W}\right)$. Similar studies using the cultivar Red Delicious were conducted on trees growing at SR and CV research orchards. Red Delicious trees growing at CV and SR orchards were planted in 2001 and 2007, respectively. Inoculum preparation and wound inoculations were conducted as described above. Twig inoculations occurred on 3 March, 1 April, 1 May, 1 September, and 1 October 2014. A total of 24 twigs per inoculation date were wound inoculated with $N$. perennans and $N$. kienholzii (12 trees of each cultivar were inoculated, but because Red Delicious trees at the SR site were young with very small branches, 24 trees of this cultivar were used). Weed and insect management was conducted in each orchard plot according to commercial production criteria typical of central Washington (Bush et al. 2008).

Two twigs per inoculation treatment were destructively harvested at 2, 4, 6, 8, 10, and 12 months postinoculation. Twigs were surface disinfested with $70 \%$ ethanol, and cankers were visually inspected for the presence of acervuli using a dissecting microscope. Acervuli were excised from cankers and transferred onto PDA, incubated at $20^{\circ} \mathrm{C}$ for 7 to 14 days, and examined visually to assess viability and verify the presence of Neofabraea spp. in culture. The proportion of twigs bearing acervuli at each harvest period were compared across inoculation date using SAS PROC GENMOD to identify a favorable period for asexual fruiting body development.

\section{Results}

Canker description. A slight expansion of wounded tissue was observed for the noninoculated control twigs particularly during winter inoculation periods when temperatures were at or below freezing. Generally, control inoculated bark tissue did not exhibit noticeable discoloration or necrosis (Fig. 1A). Canker symptoms for twigs inoculated with $N$. kienholzii (Fig. 1B) were similar in appearance to those induced by $N$. perennans (Fig. 1C). Cankers primarily expanded along the length of the twig, and less across the width of the

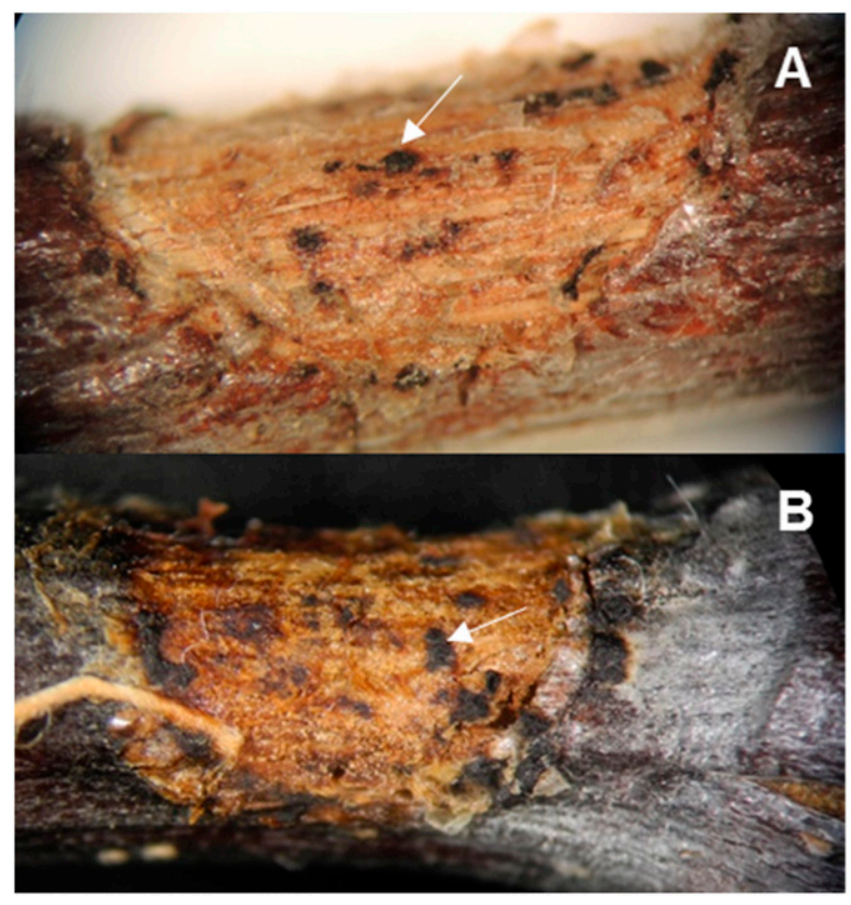

Fig. 2. Fuji apple twigs wounded and artificially inoculated with potato dextrose agar (PDA) plugs containing germinated spores of Neofabraea kienholzii (A) and $N$. perennans (B) during the month of April at the Washington State University Tree Fruit Research and Extension Center orchard plot in Wenatchee, WA. Black, bulbous structures emanating from the wound inoculation site of the twig canker represent fruiting bodies developed by the pathogen (indicated with an arrow). Photos were taken at 6 months (A) and 2 months (B) postinoculation. 
twig. Expansion was often asymmetrical, with greater canker expansion occurring from the center of the wound inoculation point to the distal end of the twig. Cankers were slightly sunken with a reddish-brown, sometimes orange-black discoloration and occasionally gave the appearance of concentric rings. Canker margins were often well defined, except when twigs demonstrated dieback symptoms. Occasionally, when canker expansion was severe, the upper bark tissue would become paper-like and gradually peel off. Sometimes tissue would become fibrous and threadlike at the point of wounding. Woolly apple aphids were often found colonizing cankers of both $N$. perennans and N. kienholzii. Acervuli were visible erupting from wounded tissue at the point of twig inoculation. Acervuli appeared black in color, round/bulbous in texture, and were similar in appearance for both Neofabraea spp. (Fig. 2).

Timing of canker induction and expansion. A significant interaction between treatment type and inoculation date was detected for both Fuji and Red Delicious apple cultivars used during the three annual trials of this study $(P<0.0001)$. In the 2012-13 trial (Table 1$)$, Red Delicious twigs inoculated with $N$. perennans in October developed cankers that were significantly larger than those induced during any of the other inoculation dates $(P \leq 0.0027)$. The second largest cankers formed in response to inoculations conducted in April $(P \leq$ 0.0003 ). When N. kienholzii was used as the inoculum source, cankers initiated in April were significantly larger in size than cankers formed at any other inoculation date $(P \leq 0.0014)$ except October $(P=0.7847)$. Overall, a noticeable reduction in canker size was observed across all inoculation dates during the 2013-14 trial (Table 2) for Red Delicious twigs compared with the 2012-13 trial. For either pathogen, canker expansion was greater when twigs were inoculated in October compared with cankers initiated in response to inoculations conducted in June $(P \leq 0.002)$ or August $(P<0.0001)$. During 2014-15 (Table 3), both $N$. perennans $(P<0.0001)$ and $N$. kienholzii $(P<0.0001)$ induced the largest cankers when twigs were inoculated in October compared with all other inoculation dates.

For Fuji twigs inoculated with either $N$. perennans or $N$. kienholzii $(P<0.0001)$ in 2012-13 (Table 4), the greatest canker expansion

Table 1. Influence of inoculation date and treatment type on average canker half-length for Red Delicious apple trees inoculated during the 2012-13 annual trial

\begin{tabular}{|c|c|c|}
\hline Inoculation date & Treatment $^{\mathbf{a}}$ & Canker half-length $(\mathrm{mm})^{\mathbf{b}}$ \\
\hline \multirow[t]{3}{*}{23 Apr 2012} & Control $^{\S}$ & 1.2 \\
\hline & Neofabraea perennans* & $14.7 \mathrm{x}$ \\
\hline & N. kienholzii ${ }^{\#}$ & $5.8 \mathrm{w}$ \\
\hline \multirow[t]{3}{*}{20 Jun 2012} & Control $^{\#}$ & 1.1 \\
\hline & N. perennans* ${ }^{*}$ & $2.4 \mathrm{yz}$ \\
\hline & N. kienholzii* & $1.9 \mathrm{y}$ \\
\hline \multirow[t]{3}{*}{23 Aug 2012} & Control $^{\#}$ & 0.9 \\
\hline & N. perennans* & $2.8 \mathrm{yz}$ \\
\hline & N. kienholziii & $1.2 \mathrm{y}$ \\
\hline \multirow[t]{3}{*}{19 Oct 2012} & Control $\$$ & 0.4 \\
\hline & N. perennans* & $27.4 \mathrm{w}$ \\
\hline & N. kienholzii & $5.3 \mathrm{wx}$ \\
\hline \multirow[t]{3}{*}{18 Dec 2012} & Control* & 0.9 \\
\hline & N. perennans* & $1.6 \mathrm{z}$ \\
\hline & N. kienholzii* & $1.2 \mathrm{y}$ \\
\hline \multirow[t]{3}{*}{19 Feb 2013} & Control $^{\#}$ & 1.1 \\
\hline & N. perennans* & $6.1 \mathrm{y}$ \\
\hline & N. kienholzii ${ }^{\#}$ & $2.3 \mathrm{xy}$ \\
\hline
\end{tabular}

a Treatment type was a significant $(P<0.0001)$ factor influencing canker growth in Red Delicious apple trees for the 2012-13 annual trial of this study. Treatments designated with the same symbol at each specific inoculation date listed are not significantly different from one another according to means separation using Tukey's honest significance test $(P \leq 0.05)$.

${ }^{\mathrm{b}}$ Twig inoculation date was a significant $(P<0.0001)$ factor influencing canker expansion in Red Delicious apple trees during the 2012-13 annual trial of this study. For a given pathogen, across all inoculation dates, canker measurements sharing the same letter are not significantly different based upon Tukey's honest significance test $(P \leq 0.05)$. occurred in response to inoculations completed in October compared with all other inoculation dates. Similar to Red Delicious, disease severity noted for Fuji twigs inoculated during the second year (2013-14) of this study was comparably lower than that obtained during the initial year (2012-13) of the study (Table 5). Canker expansion owing to $N$. perennans was greatest in response to inoculations held in October compared with all other dates $(P<0.0001)$. However, when $N$. kienholzii was used as the inoculum source, December $(P \leq 0.0004)$ and October $(P \leq 0.0107)$ inoculations resulted in cankers that were significantly larger in size than those initiated in April, June, or August. During 2014-15 (Table 6), both N. perennans and $N$. kienholzii produced the largest cankers when inoculations were conducted in October compared with all other inoculation dates $(P<0.0001)$.

Both N. perennans and N. kienholzii were successfully recovered from inoculated twigs harvested at 6 months postinoculation regardless of the time period inoculations were conducted. Although the proportion of twigs from which Neofabraea spp. were reisolated varied across inoculation date, no observable trends in pathogen recovery could be discerned. In general, the pathogen was recovered from at least $50 \%$ of the total number of twigs that were inoculated at each date evaluated. Exceptions to this include Red Delicious twigs inoculated with $N$. perennans in April 2012, December 2013, June 2014, and August 2014 for which recovery was only at $31.3,25,25$, and $37.5 \%$, respectively. For $N$. perennans inoculations conducted on Fuji, recovery of the pathogen was obtained from only $39.6,31.3$, and $37.5 \%$ of twigs inoculated in December 2013, June 2014, and February 2015, respectively. Recovery of $N$. kienholzii was below $50 \%$ for Fuji twigs inoculated in February 2015 (22.9\%). A significant difference in the relative recovery of the two pathogens was detected for inoculations conducted in December 2013, during which $N$. kienholzii was reisolated at a significantly greater frequency than $N$. perennans $(P=$ $0.0002)$. Pathogen recovery did not appear to be related to canker expansion. This was evidenced in 2012 when both $N$. perennans and N. kienholzii were recovered from $100 \%$ of twigs inoculated in August, even though average canker expansion for twigs

Table 2. Influence of inoculation date and treatment type on average canker half-length for Red Delicious apple trees inoculated during the 2013-14 annual trial

\begin{tabular}{|c|c|c|}
\hline Inoculation date & Treatment $^{\mathbf{a}}$ & Canker half-length $(\mathrm{mm})^{\mathbf{b}}$ \\
\hline \multirow[t]{3}{*}{16 Apr 2013} & Control $^{\#}$ & 1.2 \\
\hline & Neofabraea perennans* & $3.0 \mathrm{w}$ \\
\hline & N. kienholzii ${ }^{*}$ & $2.8 \mathrm{wx}$ \\
\hline \multirow[t]{3}{*}{25 Jun 2013} & Control* & 1.1 \\
\hline & N. perennans* & $1.5 \mathrm{xy}$ \\
\hline & N. kienholzii* & $1.4 \mathrm{xy}$ \\
\hline \multirow[t]{3}{*}{19 Aug 2013} & Control* & 0.8 \\
\hline & N. perennans* & $0.8 \mathrm{y}$ \\
\hline & N. kienholzii* & $0.9 \mathrm{y}$ \\
\hline \multirow[t]{3}{*}{15 Oct 2013} & Control $^{\#}$ & 0.6 \\
\hline & N. perennans* & $4.5 \mathrm{w}$ \\
\hline & N. kienholzii ${ }^{*}$ & $4.3 \mathrm{w}$ \\
\hline \multirow[t]{3}{*}{12 Dec 2013} & Control* & 2.0 \\
\hline & N. perennans* & $2.8 \mathrm{wx}$ \\
\hline & N. kienholzii* & $2.7 \mathrm{wx}$ \\
\hline \multirow[t]{3}{*}{19 Feb 2014} & Control $^{\#}$ & 1.1 \\
\hline & N. perennans* & $4.8 \mathrm{w}$ \\
\hline & N. kienholzii* & $3.4 \mathrm{w}$ \\
\hline
\end{tabular}

a Treatment type was a significant $(P<0.0001)$ factor influencing canker growth in Red Delicious apple trees for the 2013-14 annual trial of this study. Treatments designated with the same symbol at each specific inoculation date listed are not significantly different from one another according to means separation using Tukey's honest significance test $(P \leq 0.05)$.

${ }^{\mathrm{b}}$ Twig inoculation date was a significant $(P<0.0001)$ factor influencing canker expansion in Red Delicious apple trees during the 2013-14 annual trial of this study. For a given pathogen, across all inoculation dates, canker measurements sharing the same letter are not significantly different based upon Tukey's honest significance test $(P \leq 0.05)$. 
inoculated in August was slight (less than $3 \mathrm{~mm}$ ). Instead, secondary fungal saprophytes such as Cladosporium spp., Penicillium spp., and Alternaria spp. were often recovered from twig tissue and would on occasion outcompete growth of Neofabraea spp. in culture, making it difficult to detect target fungi.

Table 3. Influence of inoculation date and treatment type on average canker half-length for Red Delicious apple trees inoculated during the 2014-15 annual trial

\begin{tabular}{|c|c|c|}
\hline Inoculation date & Treatment $^{\mathrm{a}}$ & Canker half-length $(\mathbf{m m})^{b}$ \\
\hline \multirow[t]{3}{*}{17 Apr 2014} & Control $^{\#}$ & 1.0 \\
\hline & Neofabraea perennans* & $7.0 \mathrm{x}$ \\
\hline & N. kienholzii* & $4.0 \mathrm{x}$ \\
\hline \multirow[t]{3}{*}{17 Jun 2014} & Control $^{\#}$ & 0.6 \\
\hline & N. perennans* & $1.9 \mathrm{y}$ \\
\hline & N. kienholziï & $1.0 \mathrm{y}$ \\
\hline \multirow[t]{3}{*}{25 Aug 2014} & Control* & 0.7 \\
\hline & N. perennans* & $1.0 \mathrm{y}$ \\
\hline & N. kienholzii* & $1.3 \mathrm{y}$ \\
\hline \multirow[t]{3}{*}{28 Oct 2014} & Control $^{\S}$ & 0.3 \\
\hline & N. perennans* & $32.4 \mathrm{w}$ \\
\hline & N. kienholzii ${ }^{\#}$ & $17.9 \mathrm{w}$ \\
\hline \multirow[t]{3}{*}{17 Dec 2014} & Control $^{\#}$ & 1.2 \\
\hline & N. perennans* & $2.6 \mathrm{y}$ \\
\hline & N. kienholzii ${ }^{\#}$ & $1.8 \mathrm{xy}$ \\
\hline \multirow[t]{3}{*}{18 Feb 2015} & Control $^{\#}$ & 0.8 \\
\hline & N. perennans* & $5.6 \mathrm{x}$ \\
\hline & N. kienholzii* & $4.6 \mathrm{x}$ \\
\hline
\end{tabular}

a Treatment type was a significant $(P<0.0001)$ factor influencing canker growth in Red Delicious apple trees for the 2014-15 annual trial of this study. Treatments designated with the same symbol at each specific inoculation date listed are not significantly different from one another according to means separation using Tukey's honest significance test $(P \leq 0.05)$.

${ }^{\mathrm{b}}$ Twig inoculation date was a significant $(P<0.0001)$ factor influencing canker expansion in Red Delicious apple trees during the 2014-15 annual trial of this study. For a given pathogen, across all inoculation dates, canker measurements sharing the same letter are not significantly different based upon Tukey's honest significance test $(P \leq 0.05)$.

Table 4. Influence of inoculation date and treatment type on average canker half-length for Fuji apple trees inoculated during the 2012-13 annual trial

\begin{tabular}{|c|c|c|}
\hline Inoculation date & Treatment $^{\mathbf{a}}$ & Canker half-length $(\mathrm{mm})^{\mathrm{b}}$ \\
\hline \multirow[t]{3}{*}{23 Apr 2012} & Control $^{\S}$ & 1.2 \\
\hline & Neofabraea perennans* & $11.8 \mathrm{x}$ \\
\hline & N. kienholziii & $4.8 \mathrm{x}$ \\
\hline \multirow[t]{3}{*}{20 Jun 2012} & Control* & 1.6 \\
\hline & $N$. perennans* & $2.9 \mathrm{yz}$ \\
\hline & N. kienholzii* & $2.6 \mathrm{yz}$ \\
\hline \multirow[t]{3}{*}{23 Aug 2012} & Control\$ & 0.5 \\
\hline & N. perennans* & $4.6 \mathrm{y}$ \\
\hline & N. kienholziii & $1.9 \mathrm{yz}$ \\
\hline \multirow[t]{3}{*}{19 Oct 2012} & Control\$ & 0.5 \\
\hline & $N$. perennans* & $39.8 \mathrm{w}$ \\
\hline & N. kienholzii ${ }^{\#}$ & $19.0 \mathrm{w}$ \\
\hline \multirow[t]{3}{*}{18 Dec 2012} & Control* & 0.9 \\
\hline & $N$. perennans* & $1.2 \mathrm{z}$ \\
\hline & N. kienholzii* & $1.2 \mathrm{z}$ \\
\hline \multirow[t]{3}{*}{19 Feb 2013} & Control $^{\#}$ & 0.9 \\
\hline & $N$. perennans ${ }^{*}$ & $4.7 \mathrm{y}$ \\
\hline & N. kienholzii* & $3.9 x y$ \\
\hline
\end{tabular}

a Treatment type was a significant $(P<0.0001)$ factor influencing canker growth in Fuji apple trees for the 2012-13 annual trial of this study. Treatments designated with the same symbol at each specific inoculation date listed are not significantly different from one another according to means separation using Tukey's honest significance test $(P \leq 0.05)$.

${ }^{\mathrm{b}}$ Twig inoculation date was a significant $(P<0.0001)$ factor influencing canker expansion in Fuji apple trees during the 2012-13 annual trial of this study. For a given pathogen, across all inoculation dates, canker measurements sharing the same letter are not significantly different based upon Tukey's honest significance test $(P \leq 0.05)$.
Development of acervuli on inoculated apple twigs. Acervuli developed in response to all inoculation periods except Fuji twigs inoculated with $N$. perennans during March at the TFREC orchard, Fuji twigs inoculated with $N$. kienholzii during March at the CV orchard, and Red Delicious twigs inoculated with $N$. perennans

Table 5. Influence of inoculation date and treatment type on average canker half-length for Fuji apple trees inoculated during the 2013-14 annual trial

\begin{tabular}{|c|c|c|}
\hline Inoculation date & Treatment $^{\mathrm{a}}$ & Canker half-length $(\mathrm{mm})^{\mathrm{b}}$ \\
\hline \multirow[t]{3}{*}{16 Apr 2013} & Control $^{\#}$ & 1.9 \\
\hline & Neofabraea perennans* & $4.8 \mathrm{xy}$ \\
\hline & N. kienholzii ${ }^{\#}$ & $2.2 \mathrm{xy}$ \\
\hline \multirow[t]{3}{*}{25 Jun 2013} & Control* & 0.9 \\
\hline & N. perennans* & $1.1 \mathrm{z}$ \\
\hline & N. kienholzii ${ }^{*}$ & $1.3 \mathrm{y}$ \\
\hline \multirow[t]{3}{*}{19 Aug 2013} & Control $^{\#}$ & 0.5 \\
\hline & N. perennans* & $1.2 \mathrm{z}$ \\
\hline & N. kienholzii ${ }^{\#}$ & $0.8 \mathrm{y}$ \\
\hline \multirow[t]{3}{*}{15 Oct 2013} & Control $^{\S}$ & 1.4 \\
\hline & N. perennans* & $16.5 \mathrm{w}$ \\
\hline & N. kienholzii ${ }^{\#}$ & $6.3 \mathrm{w}$ \\
\hline \multirow[t]{3}{*}{12 Dec 2013} & Control $^{\#}$ & 3.9 \\
\hline & N. perennans $\#$ & $3.4 \mathrm{y}$ \\
\hline & N. kienholzii* & $8.1 \mathrm{w}$ \\
\hline \multirow[t]{3}{*}{19 Feb 2014} & Control $^{\#}$ & 1.2 \\
\hline & N. perennans* & $7.2 \mathrm{x}$ \\
\hline & N. kienholzii* & $6.1 \mathrm{wx}$ \\
\hline
\end{tabular}

a Treatment type was a significant $(P<0.0001)$ factor influencing canker growth in Fuji apple trees for the 2013-14 annual trial of this study. Treatments designated with the same symbol at each specific inoculation date listed are not significantly different from one another according to means separation using Tukey's honest significance test $(P \leq 0.05)$.

${ }^{\mathrm{b}}$ Twig inoculation date was a significant $(P<0.0001)$ factor influencing canker expansion in Fuji apple trees during the 2013-14 annual trial of this study. For a given pathogen, across all inoculation dates, canker measurements sharing the same letter are not significantly different based upon Tukey's honest significance test $(P \leq 0.05)$.

Table 6. Influence of inoculation date and treatment type on average canker half-length for Fuji apple trees inoculated during the 2014-15 annual trial

\begin{tabular}{|c|c|c|}
\hline Inoculation date & Treatment $^{\mathbf{a}}$ & Canker half-length $(\mathrm{mm})^{\mathbf{b}}$ \\
\hline \multirow[t]{3}{*}{17 Apr 2014} & Control $^{\#}$ & 1.5 \\
\hline & Neofabraea perennans* & $9.1 \mathrm{x}$ \\
\hline & N. kienholzii* & $4.7 \mathrm{x}$ \\
\hline \multirow[t]{3}{*}{17 Jun 2014} & Control* & 0.8 \\
\hline & N. perennans* & $1.3 \mathrm{y}$ \\
\hline & N. kienholzii* & $1.1 \mathrm{y}$ \\
\hline \multirow[t]{3}{*}{25 Aug 2014} & Control $^{\#}$ & 0.7 \\
\hline & N. perennans* & $2.0 \mathrm{y}$ \\
\hline & N. kienholzii ${ }^{\#}$ & $1.1 \mathrm{y}$ \\
\hline \multirow[t]{3}{*}{28 Oct 2014} & Control$^{\S}$ & 0.6 \\
\hline & N. perennans* & $37.0 \mathrm{w}$ \\
\hline & N. kienholzii & $22.3 \mathrm{w}$ \\
\hline \multirow[t]{3}{*}{ 17 Dec 2014} & Control $^{\#}$ & 0.9 \\
\hline & N. perennans* & $3.6 \mathrm{xy}$ \\
\hline & N. kienholzii* & $4.0 \mathrm{x}$ \\
\hline \multirow[t]{3}{*}{18 Feb 2015} & Control $^{\#}$ & 0.8 \\
\hline & N. perennans* & $3.8 \mathrm{xy}$ \\
\hline & N. kienholzii* & $2.8 \mathrm{x}$ \\
\hline
\end{tabular}

a Treatment type was a significant $(P<0.0001)$ factor influencing canker growth in Fuji apple trees for the 2014-15 annual trial of this study. Treatments designated with the same symbol at each specific inoculation date listed are not significantly different from one another according to means separation using Tukey's honest significance test $(P \leq 0.05)$.

${ }^{b}$ Twig inoculation date was a significant $(P<0.0001)$ factor influencing canker expansion in Fuji apple trees during the 2014-15 annual trial of this study. For a given pathogen, across all inoculation dates, canker measurements sharing the same letter are not significantly different based upon Tukey's honest significance test $(P \leq 0.05)$. 
during October at the $\mathrm{CV}$ orchard. Inoculation date was a significant variable influencing acervuli development at TFREC (N. kienholzii, $P=0.0174 ; N$. perennans, $P=0.0012$ ) and CV Fuji (N. kienholzii, $P=0.0290 ; N$. perennans, $P=0.0085$ ) orchards. Neither inoculation date, harvest period, nor an interaction between the two variables was significant at SR or CV Red Delicious orchards.

For Fuji trees growing at TFREC orchard (Fig. 3A), more twigs developed acervuli in response to inoculations conducted in April for $N$. kienholzii $(P=0.0321)$ and in September for $N$. perennans $(P=$ 0.0043 ) compared with the other inoculation dates evaluated in this study. For Fuji trees growing at $\mathrm{CV}$ orchard, a greater proportion of twigs developed acervuli following inoculations with $N$. perennans $(P=0.0200)$ conducted in April (Fig. 3B). Although inoculation date was considered to be a significant variable influencing acervuli development at $\mathrm{CV}$ orchard following twig inoculations with $N$. kienholzii $(P=0.0290)$, none of the inoculation dates were significantly different from one another (Fig. 3D). Similarly, inoculation date was not significant for Red Delicious twigs growing at SR orchard (Fig. 3C).

\section{Discussion}

In this study, Red Delicious and Fuji apple twigs wound inoculated with $N$. kienholzii developed a canker disease that was similar in behavior and appearance to perennial canker of apple trees caused by $N$. perennans. Cankers induced by either pathogen were more likely to arise from inoculations conducted in October compared with all other inoculation dates tested in this study. Expansion of cankers initiated in October was often rapid, causing maximum damage to host tissue. Inoculations conducted during the summer (June and August) were less likely to yield twig cankers that extended in size beyond the wound inoculation site. These results are consistent with the findings of Shear and Cooley (1933), Grove et al. (1992), and Henriquez et al. (2006), in which apple and pear trees inoculated with Neofabraea spp. demonstrated a higher propensity for canker development in response to inoculations conducted during autumn months. Both Grove et al. (1992) and Henriquez et al. (2006) reported winter as an additional important period for canker development. However, in the present study, twigs inoculated in December rarely developed obvious canker symptoms. Rather, twigs demonstrating tissue necrosis and dieback presumably resulted owing to cold injury, because these symptoms occurred on both pathogen-inoculated and mock-inoculated twigs. Although perennial canker can also lead to dieback of infected twigs and branches, these symptoms observed in association with December inoculations may have developed as a synergistic response between wounding and winter injury. This
A

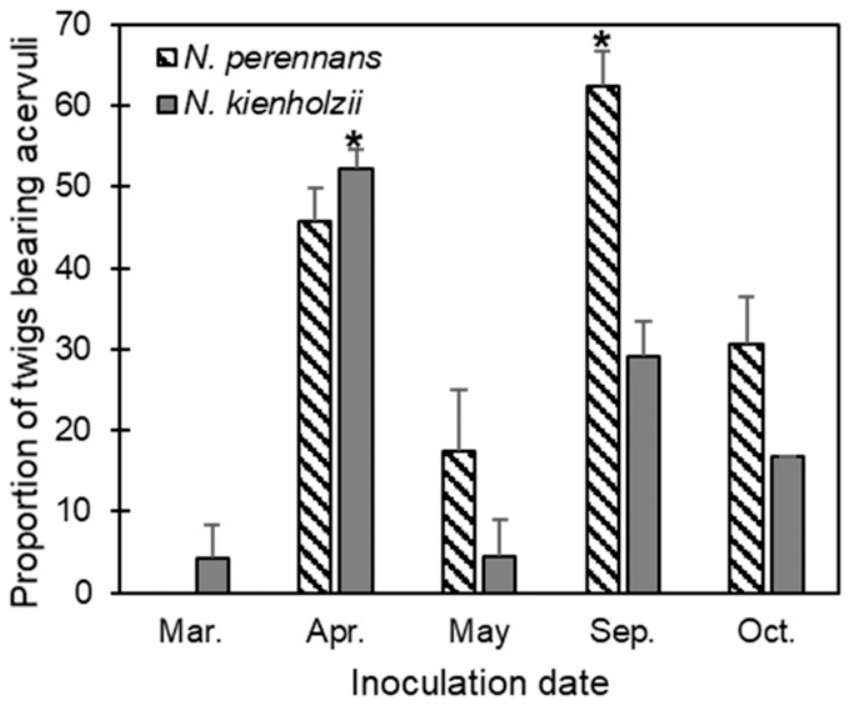

C

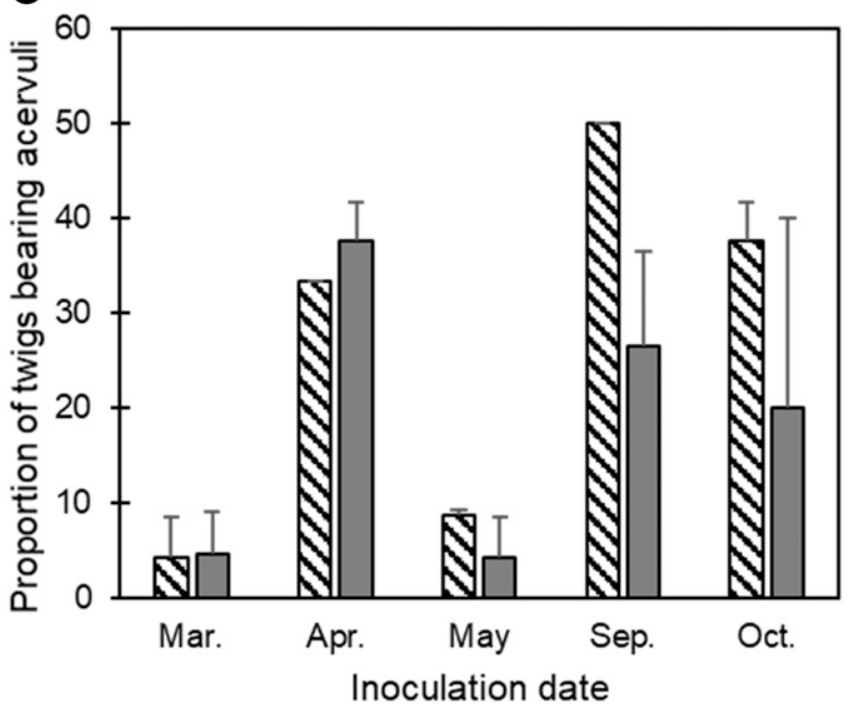

B

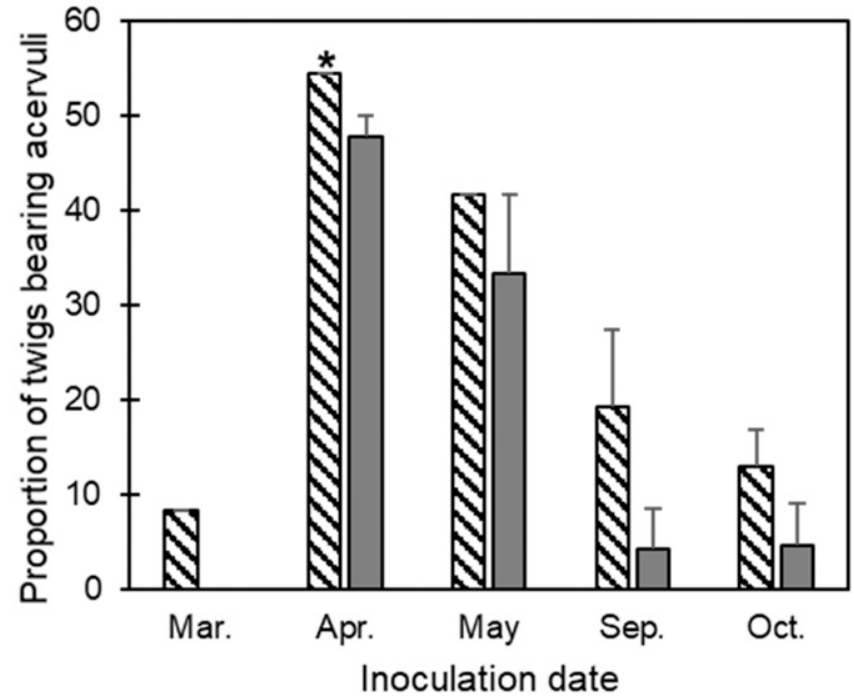

D

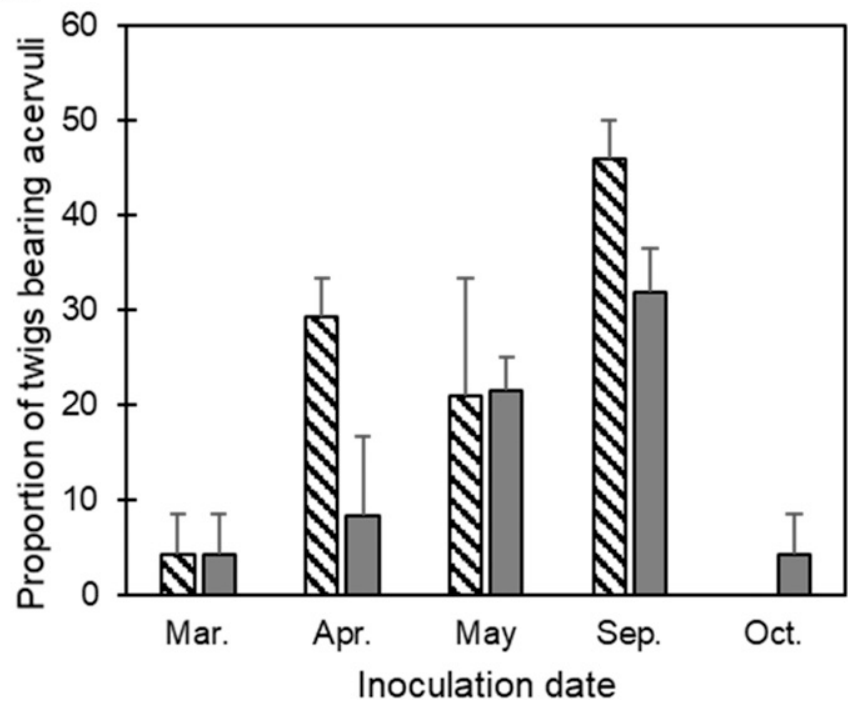

Fig. 3. Effect of inoculation date on the average proportion of Fuji (A and B) and Red Delicious ( $\mathbf{C}$ and $\mathbf{D})$ apple twigs producing the asexual fruiting body of Neofabraea perennans and N. kienholzii following artificial wound inoculations conducted at orchard plots located at the Washington State University Tree Fruit Research and Extension Center (A), Columbia View (B and D), and Sunrise $(C)$ research orchards near Wenatchee, WA. Error bars indicate the standard error of the mean. 
interaction can help explain why wound expansion was observed for Fuji twigs inoculated with the control treatment during December 2013. However, this potential interaction does not completely explain differences in canker expansion between the three treatments for twigs inoculated in December 2014.

In the current study, half-length canker size was used as an indicator of fungal activity in host tissue. This unit of measurement ignores fungal activity occurring on the distal end of infected twigs and may explain the discrepancy between our findings and those of previous studies (Grove et al. 1992; Henriquez et al. 2006). Sizeable cankers were also noted on twigs inoculated in mid-February and April, albeit not as large as those produced in response to October inoculations. Increased activity of these fungi in cankers of pome fruit trees during autumn appears to correspond well with previous reports of higher fruit infection rates observed near the end of harvest as opposed to other months during the fruit-growing season (Aguilar et al. 2017; Henriquez et al. 2008). These findings also are consistent with observations made by Miller (1932), who demonstrated that Neofabraea spp. are capable of growing on apples and artificial media at a temperature range between 0 and $30^{\circ} \mathrm{C}$, but they grow best as temperatures approach $20^{\circ} \mathrm{C}$. Cankers initiated in spring might also relate to the condition of a weakened host predisposed to infection by winter stress, or in response to nutrient availability in woody tissues following a break from winter dormancy.

During periods favorable to canker development, twig cankers incited by $N$. kienholzii were overall comparatively smaller than those initiated by $N$. perennans. This suggests $N$. kienholzii may not be as aggressive a pathogen of bark tissue as $N$. perennans. This characteristic could be responsible for the generally lower frequency of incidence in which $N$. kienholzii has been reported as a causal agent of bull's-eye rot in the Pacific Northwest relative to other species of Neofabraea and related fungi (Spotts et al. 2009). However, inoculation studies using $N$. malicorticis and $N$. perennans in bark tissue of apple trees by Kienholz (1939) revealed considerable variation in canker development between strains of a single species. Given that pathogenicity is a multifaceted and dynamic process and that only a single isolate of $N$. kienholzii was examined in the current study, potential still exists for $N$. kienholzii to emerge as an important causal agent of bull's-eye rot and canker of pome fruit trees in the Pacific Northwest. Since its original identification as a putative Neofabraea spp. among isolates collected from Nova Scotia and Portugal (de Jong et al. 2001), N. kienholzii has been reported in plant materials collected from Australia (Cunnington 2004), the Pacific Northwest region of the United States (Henriquez et al. 2004; Spotts et al. 2009), Poland (Michalecka et al. 2015), the Czech Republic (Pešicová et al. 2016), the Netherlands (Wenneker et al. 2017), and the United Kingdom (Kingsnorth et al. 2017). Whether these reports indicate current international spread of the pathogen or merely reflect improvements in molecular diagnostics is difficult to determine. Genetic analysis of $N$. kienholzii populations throughout pome fruit production regions could help elucidate the level of diversity existing within this species and could assist in the formulation of predictions as to the threat this fungus poses to apple production.

In addition to canker expansion, autumn and spring were equally favorable periods for asexual fruiting body development of N. kienholzii and N. perennans. Although conidia production was not monitored over the course of this study, previous reports noted abundant acervuli production in cankers of Neofabraea spp. from October through February (Henriquez et al. 2006), with the greatest sporulation occurring near the end of summer (Henriquez et al. 2008) and lasting until winter (Grove et al. 1992). Sporulation and spore dispersal are enhanced during periods of heavy rainfall and humidity (Edney 1956). When this type of atmospheric activity overlaps with fruit development and maturity, fruit infection is highly likely. The fact that Neofabraea spp. can produce acervuli regardless of when twig inoculation occurred and the fact that the pathogen could be recovered from inoculated twigs 6 months postinoculation indicate that these fungi are resilient to diverse environmental conditions experienced in the orchard. Once established in an orchard, the overseasoning potential and chance for inoculum spread are high.
Current recommendations for control of perennial canker involve the implementation of cultural orchard management practices. This includes canker removal through tree pruning, protecting trees so that wounding and injuries are kept to a minimum, control strategies that help mitigate aphid populations, and use of orchard sanitation practices that minimize the inoculum load of Neofabraea spp. in the orchard (Grove et al. 1992). In the U.S. Pacific Northwest, apple trees are horticulturally pruned near the end of winter through the beginning of spring. Pruning helps maintain tree structure and canopy shape, and it also helps promote air circulation throughout the tree canopy, creating a less favorable microclimate for fungal infection. Additionally, pruning enables the removal of infected or otherwise unhealthy tree branches, which in turn helps reduce the fungal inoculum load within the orchard. Because pruning occurs during the months when Neofabraea spp. have been reported to remain active in the orchard, proper pruning techniques should be employed at all times so as to minimize tree injury and ensure damage to branch collars is avoided. Such techniques will stimulate pruning wounds to heal in a healthy manner, making the wound less vulnerable to fungal invasion (Shigo 1984). Although reports from this and previous studies (Grove et al. 1992; Henriquez et al. 2006) indicate Neofabraea spp. are less active during summer months, from a horticultural standpoint, pruning during the summer should be avoided and reserved for situations when canker development on tree limbs is obvious and severe, and it is economically beneficial to do so.

In addition to employing proper pruning techniques, aphid populations in the orchard need to be managed and kept to a minimum. Woolly apple aphids in particular have been shown to feed on tree cankers and pruning wounds, inducing feeding galls that cause bark tissue to rupture following exposure to freezing temperatures (Grove et al. 1992). Aphid feeding wounds then serve as potential points of entry that can be colonized by Neofabraea spp. or similar cankerinducing fungi. Because woolly apple aphids were noted colonizing cankers induced by both $N$. perennans and $N$. kienholzii alike, it is highly probable that activities of this insect can exacerbate the disease cycle of Neofabraea species. Therefore, any beneficial effects achieved through pruning can quickly become negated unless aphid populations are kept in check. Additional studies characterizing the relationship between woolly apple aphids and $N$. kienholzii canker development and disease control are required to effectively address these premises.

\section{Acknowledgments}

Our heartfelt appreciation is extended to R. Boal, M. Walter, and P. Sikdar for help during the conduct of these experiments. Many thanks to the individuals who reviewed this manuscript and provided valuable feedback.

\section{Literature Cited}

Aguilar, C. G., Mazzola, M., and Xiao, C. L. 2017. Timing of apple fruit infection by Neofabraea perennans and Neofabraea kienholzii in relation to bull's-eye rot development in stored apple fruit. Plant Dis. 101:800-806.

Bush, M. J., Dunley, J., Beers, E. H., Brunner, J. F., Grove, G. G., Xiao, C. L., Elfving, D. C., Peryea, F., Schrader, L., Parker, R., Smith, T. J., Daniels, C., Maxwell, T., Foss, S. L., Johnson, E., and Tangren, J. 2008. 2008 Crop Protection Guide for Tree Fruits in Washington. Bulletin EB 0419. Washington State University Extension, Pullman.

Cameldi, I., Ceredi, G., Spadoni, A., Ventrucci, D., and Mari, M. 2014. Lenticel rot of apple fruit caused by Phlyctema vagabunda (ex Gloeosporium album): Epidemiological aspects and disease management. Pages 93-102 in: Atti, giornate fitopatologiche, chianciano terme (Siena), 18-21 Marzo 2014. A. Brunelli and M. Collina, eds. Alma Mater Studiorum, Universitá di Bologna, Bologna, Italy.

Chen, C., Verkley, G. J. M., Sun, G., Groenewald, J. Z., and Crous, P. W. 2016 Redefining common endophytes and plant pathogens in Neofabraea, Pezicula, and related genera. Fungal Biol. 120:1291-1322.

Childs, L. 1929. The Relation of Woolly Apple Aphids to Perennial Canker Infection with Other Notes on the Disease. Bulletin 243. Oregon Agricultural Experiment Station, Corvallis.

Cordley, A. B. 1900. Some observations on apple tree anthracnose. Bot. Gaz. Crawfordsville 30:48-58.

Cunnington, J. H. 2004. Three Neofabraea species on pome fruit in Australia. Australas. Plant Pathol. 33:453-454.

de Jong, S. N., Levesque, C. A., Verkley, G. J. M., Abelin, E. C. A., Rahe, J. E., and Braun, P. G. 2001. Phylogenetic relationships among Neofabraea species 
causing tree cankers and bull's eye rot of apples based on DNA sequencing of ITS nuclear rDNA, mitochondrial rDNA, and the $\beta$-tubulin gene. Mycol. Res. 105:658-669.

Dugan, F., Grove, G. G., and Rogers, J. D. 1993. Comparative studies of Cryptosporiopsis curvispora and C. perennans. I. Morphology and pathogenic behavior. Mycologia 85:551-564.

Edney, K. L. 1956. The rotting of apples by Gloeosporium perennans Zeller \& Childs. Ann. Appl. Biol. 44:113-128.

Gariépy, T. D., Lévesque, C. A., de Jong, S. N., and Rahe, J. E. 2003. Species specific identification of the Neofabraea pathogen complex associated with pome fruits using PCR and multiplex DNA amplification. Mycol. Res. 107: 528-536.

Garton, W., Dugan, F., Mazzola, M., and Miles, C. 2016. Apple anthracnose. Washington State University Tree Fruit Extension.

Grove, G. G. 1990. Anthracnose and perennial canker. Pages 36-38 in: Compendium of Apple and Pear Diseases. A. L. Jones and H. S. Aldwinckle, eds. American Phytopathological Society, St. Paul, MN.

Grove, G. G., Dugan, F. M., and Boal, R. J. 1992. Perennial canker of apple: Seasonal host susceptibility, and perennation of Cryptosporiopsis perennans in infected fruit in eastern Washington. Plant Dis. 76:1109-1114.

Guthrie, E. J. 1959. The occurrence of Pezicula alba sp. nov. and P. malicorticis, the perfect states of Gloeosporium album and G. perennans, in England. Trans. Br. Mycol. Soc. 42:502-506.

Henriquez, J. L., Sugar, D., and Spotts, R. A. 2004. Etiology of bull's eye rot of pear caused by Neofabraea spp. in Oregon, Washington, and California. Plant Dis. 88:1134-1138.

Henriquez, J. L., Sugar, D., and Spotts, R. A. 2006. Induction of cankers on pear tree branches by Neofabraea alba and $N$. perennans, and fungicide effects on conidial production on cankers. Plant Dis. 90:481-486.

Henriquez, J. L., Sugar, D., and Spotts, R. A. 2008. Effects of environmental factors and cultural practices on bull's eye rot of pear. Plant Dis. 92:421-424.

Kidd, M. N., and Beaumont, B. A. 1924. Apple rot fungi in storage. Trans. Br. Mycol. Soc. 10:98-118.

Kienholz, J. R. 1939. Comparative study of apple anthracnose and perennial canker fungi. J. Agric. Res. 59:635-665.

Kingsnorth, J., Perrine, J., Berrie, A., and Saville, R. 2017. First report of Neofabraea kienholzii causing bull's eye rot of apple in the UK. New Dis. Rep. 36:15.

Michalecka, M., Bryk, H., Poniatowska, A., and Puławska, J. 2015. Identification of Neofabraea species causing bull's eye rot of apple in Poland and their direct detection in apple fruit using multiplex PCR. Plant Pathol. 65:643-654.
Miller, E. V. 1932. Some physiological studies of Gloeosporium perennans and Neofabraea malicorticis. J. Agric. Res. 45:65-77.

Pešicová, K., Kolařík, M., Hortová, B., and Novotný, D. 2016. Diversity and identification of Neofabraea species causing bull's eye rot in the Czech Republic. Eur. J. Plant Pathol. 147:683-693.

Pscheidt, J. W., and Ocamb, C. M. 2016. Apple (Malus spp.) anthracnose (bull'seye rot). Pacific Northwest Plant Disease Management Handbook. Oregon State University, Corvallis. https://pnwhandbooks.org/plantdisease/host-disease/ apple-malus-spp-anthracnose-bulls-eye-rot.

Putnam, M. L., and Adams, G. C. 2005. Phlyctema vagabunda causes coin canker of ash (Fraxinus spp.) in North America. Plant Dis. 89:773.

Romero, J., Raya, M. C., Roca, L. F., Moral, J., and Trapero, A. 2016. First report of Neofabraea vagabunda causing branch cankers on olives in Spain. Plant Dis. 100:527.

Rooney-Latham, S., Gallegos, L. L., Vossen, P. M., and Gubler, W. D. 2013. First report of Neofabraea alba causing fruit spot on olive in North America. Plant Dis. 97:1384.

Rooney-Latham, S., and Soriano, M. C. 2016. First report of Neofabraea alba causing branch canker dieback of apple in California. Plant Dis. 100:1011.

Shear, E. V., and Cooley, J. S. 1933. Relation of growth cycle and nutrition to perennial apple canker infection. (Abstr.) Phytopathology 23:33.

Shigo, A. 1984. Compartmentalization: A conceptual framework for understanding how trees grow and defend themselves. Annu. Rev. Phytopathol. 22:189-214.

Soto-Alvear, S., Lolas, M., Rosales, I. M., Chávez, E. R., and Latorre, B. A. 2013 Characterization of the bull's-eye rot of apple in Chile. Plant Dis. 97:485-490.

Spotts, R. A., Seifert, K. A., Wallis, K. M., Sugar, D., Xiao, C. L., Serdani, M., and Henriquez, J. L. 2009. Description of Cryptosporiopsis kienholzii and species profiles of Neofabraea in major pome fruit-growing districts in the Pacific Northwest USA. Mycol. Res. 113:1301-1311.

Tan, A. M., and Burchill, R. T. 1972. The infection and perennation of the bitter rot fungus, Gloeosporium album, on apple leaves. Ann. Appl. Biol. 70:199-206.

Verkley, G. J. M. 1999. A monograph of the genus Pezicula and its anamorphs. Stud. Mycol. 44:1-180.

Vico, I., Duduk, N., Vasić, M., Zebeljan, A., and Radivojević, D. 2016. Bull's eye rot of apple fruit caused by Neofabraea alba. Acta Hortic. 1139:733-738.

Wenneker, M., Pham, K. T. K., Boekhoudt, L. C., da Boer, F. A., van Leeuwen, P. J., Hollinger, T. C., and Thomma, B. P. H. J. 2017. First report of Neofabraea kienholzii causing bull's eye rot on pear (Pyrus communis) in the Netherlands. Plant Dis. 101:634

Zeller, S. M., and Childs, L. 1925. Perennial Canker of Apple Trees (a Preliminary Report). Bulletin 217. Oregon Agricultural Experiment Station, Corvallis. 